\title{
Oncocytic Meningioma: A Case Report
}

\author{
Adele Caldarella', Anna Maria Buccoliero', Mirca Marini², \\ Antonio Taddei ${ }^{3}$, Pasquale Mennonna ${ }^{4}$, Gian Luigi Taddei ${ }^{1}$ \\ 'Dipartimento di Patologia Umana e Oncologia, Università degli Studi di Firenze; \\ 2Dipartimento di Anatomia e Medicina Legale, Università degli Studi di Firenze; \\ ${ }^{3}$ Dipartimento di Area Critica Medico-Chirurgica-Sezione Chirurgia \\ Generale e DC, Firenze; \\ ${ }^{4}$ Dipartimento di Neurochirurgia, Azienda Ospedaliera Careggi, Firenze, Italy
}

\section{Summary}

Oncocytic meningioma is a recently described rare variant of meningothelial neoplasms that typically occurs as a large cell tumor with granular cytoplasm.

The distinct histological features of numerous cells with granular cytoplasm and the ultrastructural evidence of numerous mitochondria in the cytoplasm differentiate this tumor from other neoplasms with granular appearance.

We report an additional case of oncocytic meningioma investigated by ultrastructural and immunohistochemical methods.

Key words: Meningioma - Oncocytoma

Abbreviations: GFAP = glial fibrillar acid protein, $\mathrm{EMA}=$ epithelial membrane antigen, $\mathrm{CK}=$ cytokeratin, VIM = vimentin $; \mathrm{EM}=$ electron microscopy

\section{Introduction}

The presence of numerous oncocytic cells with cytoplasm rich in large mitochondria and prominent cristae allows us to define some tumors as "oncocytoma". Tumors showing a predominance of oncocytic cells have been reported in numerous organs, including the kidney, thyroid, salivary gland and, less commonly, breast, pancreas, liver, lung, prostate, adrenals, parathyroid, and larynx $[2,4,7,12,16]$. Most benign and malignant oncocytic tumors are of epithelial origin; oncocytic differentiation has been documented even in some mesenchymal tumors [6].
Oncocytic changes are rare within the central nervous system and are limited to neoplasms of the choroid plexus and pituitary gland. Seven cases of tumors of meningothelial origin largely composed of cells with morphological and ultrastructural features of oncocytic differentiation have recently been described $[2,13]$.

We present a case of oncocytic meningioma occurring in a 30-year-old-man.

\section{Clinical History}

A 30 year-old-man was admitted to our hospital in March 2001 for examination after a sudden appearance of neurological symptoms. The young man reported paresthesias on his legs, arms, tongue, lips, and difficult coordination of walking. The symptoms persisted for some minutes; then the patient completely recovered.

The patient never suffered from any other significant disease.

During hospitalization, neurological examination was negative, but MRI revealed an expansive lesion located in right parietal region and attached to the dura (Fig. 1). The nodule showed hypointensity in T1-weighted images and hyperintensity in T2-weighted images; in addition, it was enhanced with contrast. Surgery was performed; multiple fragments, two of the lesion and one of the dura with diameters ranging from $0.5 \mathrm{~cm}$ to $5 \mathrm{~cm}$,

Address for correspondence: Gian Luigi Taddei, Dipartimento di Patologia Umana e Oncologia, Università degli Studi di Firenze, viale Gian Battista Morgagni, 85, 50134, Firenze, Italy.

Tel.: +39+055-413756, Fax: +39+055-4379868.

E-mail: gl.taddei@unifi.it 

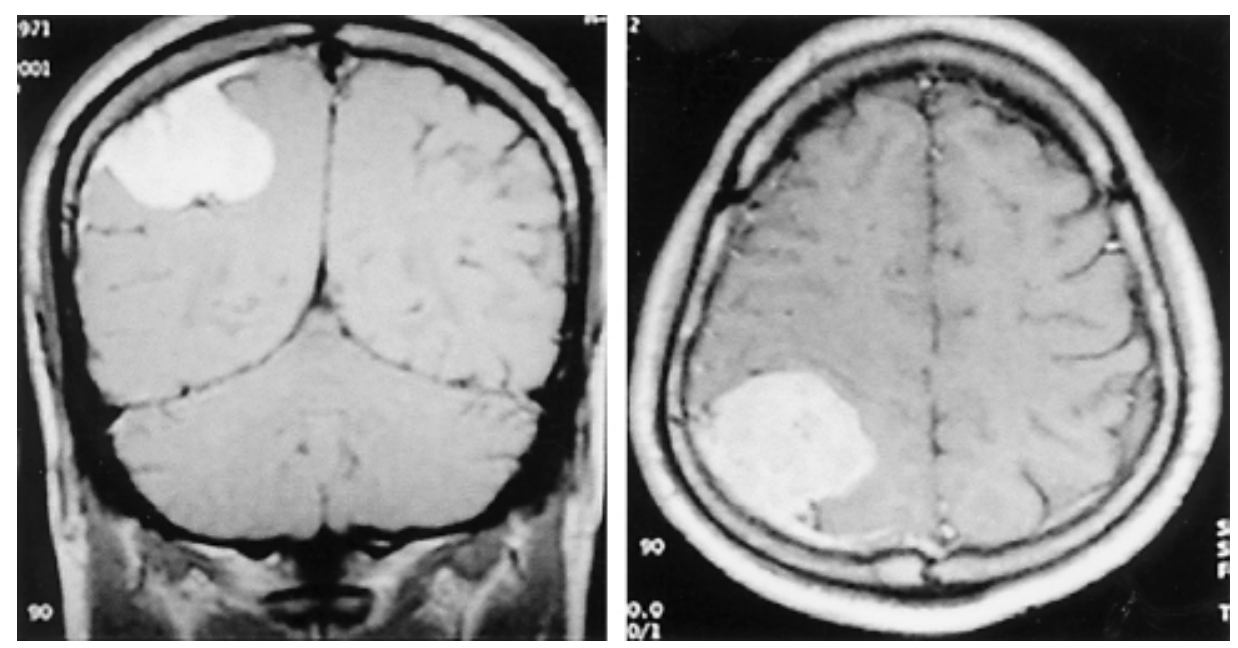

Fig. 1. Magnetic Resonance Imaging shows a dura-attached lesion in the right parietal lobe.

were sent to our department for histological examination.

Eight months later, there was no evidence of recurrence.

\section{Materials and Methods}

All submitted tissues were examined. Tissue evaluated by light microscopy was fixed in $10 \%$ neutral buffered formalin, processed, and embedded in paraffin. Histological sections were stained using hematoxylin-eosin. Immunohistochemical staining using the avidin-biotin peroxidase method was done on paraffin sections. The antibody reagents used included EMA (Dako, Glostrup, Denmark; diluted 1:50), VIM (Biogenex, San Roman, CA; diluted 1:2000), CK (Biogenex, San Roman, CA; diluted 1:200), p53 (Dako; Glostrup, Denmark diluted 1:40), S-100 (Dako, Glostrup, Denmark;, diluted 1:2000), actin (Sigma Chemical, St. Louis, MO; diluted 1:3000), GFAP (Zymed, San Francisco, CA; prediluted), thyroglobulin (Biogenex, San Roman, CA; diluted 1:100), Ki67 (Dako, Glostrup, Denmark; diluted 1:80). Ultrastructural study was done on formalin-fixed tissue, postfixed in $1 \%$ osmium tetroxide in cacodylate buffer, dehydrated in graded concentrations of ethanol, and embedded in epon. To select the fields, semithin sections were stained with toluidine blue. Ultrathin sections were cut using a diamond knife on an Ultracut R (Leica) ultramicrotome and double-stained with uranyl and lead salts. Sections were then examined with a Philips 410 LS transmission electron microscope.

\section{Results}

Histologically, the lesion was primarily composed of sheets, nests, and cords of neoplastic elements delimited by fibrous connective tissue rich in vessels (Fig. 2). Most neoplastic cells were polygonal with distinct cytoplasmic borders and had finely granular eosinophilic cytoplasm. These eosinophilic cells with granular cytoplasm constituted more than $75 \%$ of the total neoplastic population. Nuclei were round to ovoid, often centrally located; nuclear inclusions and prominent nucleoli were occasionally present. Mitoses were 2 for 20 high power fields and necrosis was absent. There was no infiltration of the dura and cerebral parenchima. Thus, the WHO criteria of atypia were not fulfilled.

The cytoplasm stained with anti-epithelial membrane antigen and anti-vimentin; only 5\% of neoplastic cells reacted with anti-cytokeratin. There was no reactivity for anti-S-100, GFAP, thyroglobulin, actin, and p53. Anti-Ki67 antiserum stained nuclei with $10 \%$ positivity.

Electron microscopy (EM) demonstrated cytoplasmic accumulation of a large number of mitochondria that appeared swollen, with flattened cristae (Fig. 3). In addition, cytoplasmic interdigitations and desmosomes were present.

The microscopic and ultrastructural findings were suggestive of a meningothelial lesion with oncocytic differentiation.

\section{Discussion}

In 1962, Hamperl designated oncocytes as a special type of epithelial cell showing cytoplasm densely filled with acidophilic granules [8]. At the EM level, cells showed numerous mitochondria in the cytoplasm, some of which often had an abnormal appearance, were swollen, or had flattened cisternae [13].

Oncocytes have been reported in the normal state of health in most organs. Appearing in small number, these granular eosinophilic cells are normal occupants of the parathyroid glands, major and minor salivary glands, lacrimal glands, and mucous glands of the aerodigestive tract.

They occasionally occur as part of a reactive, inflammatory or hyperplastic lesion, and are called oncocytic changes; oncocytosis appears to be a degenerative aging phenomenon, perhaps as an error in oxidative metabolism [10]. 

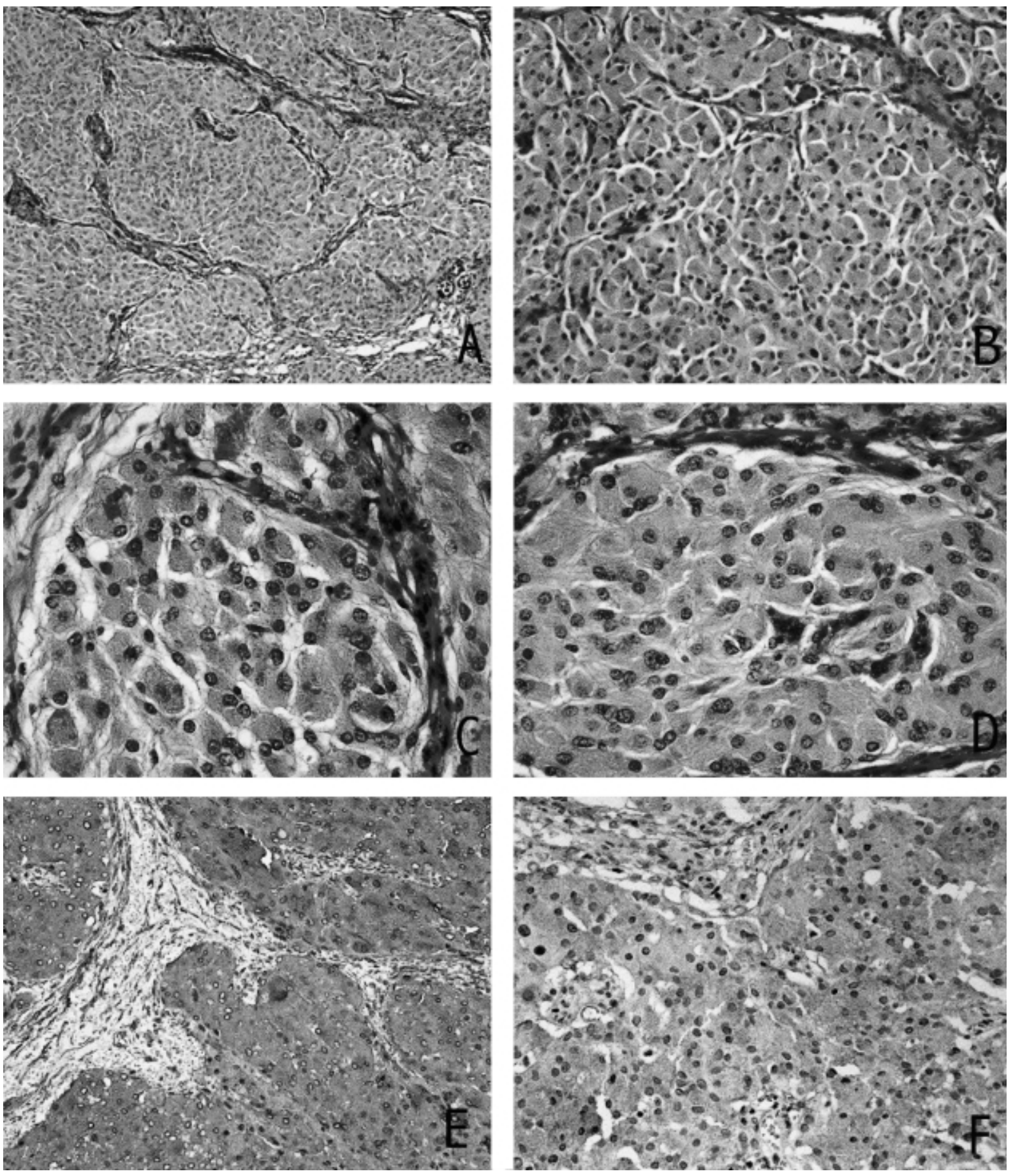

Fig. 2. Tumor is predominantly composed of sheets of rounded cells with granular eosinophilic cytoplasm (H\&E: A, B, C, D). Oncocytic meningothelial cells are immunoreactive for anti-vimentin (E) and anti-epithelial membrane antigen $(\mathrm{F})$ antisera.

Oncocytic metaplasia occurs in many unrelated tumors; neoplasms composed predominantly or exclusively of oncocytic cells have been reported in some organs and are called "oncocytic tumors" when oncocytes represent not less than $75 \%$ of cells $[1,6,13,16]$.

Oncocytoid appearance may occasionally derive from the cytoplasmic accumulation of other singular in- clusions such as lysosomes, as in granular cell tumors of soft tissue, breast, and the aerodigestive system. In other cases, as in some neuroendocrine lung carcinomas or in acidophilic pituitary adenomas, neurosecretory granules are present in the cytoplasm [10].

Several regions of the body may show diverse primary tumors with both oncocytic and oncocytoid features. 


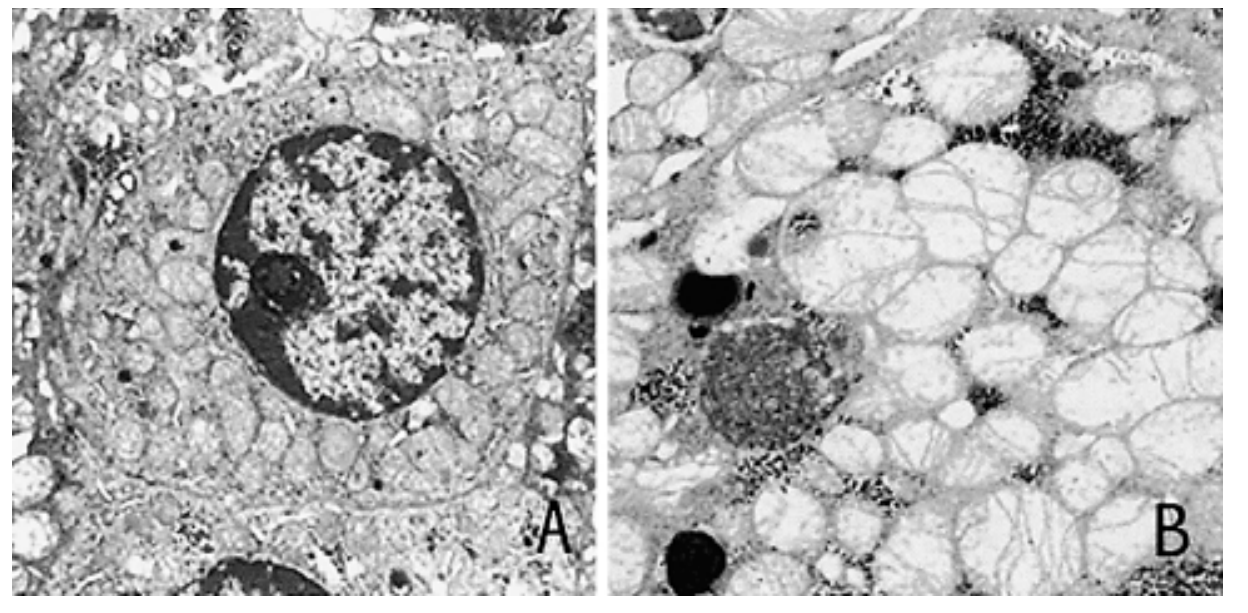

Fig. 3. On electron microscopy, numerous swollen mitochondria are seen in the cytoplasm of the granular cells. Original magnification $\times 8,000(\mathrm{~A}, \mathrm{~B})$.
Of the human intracranial tumors, oligodendrogliomas, intracranial schwannomas, and astrocytomas have been reported to show granular cell foci. Ultrastructurally, all these tumor types are rich in lysosomes, as is the granular cell tumor of infundibulum $[6,13,15]$.

Granular cells are present even in meningiomas. In 1989, Russel and Rubinstein showed that finely granular cytoplasm was one of the possible cytological features of syncytial meningiomas [14]. In 1977, other authors reported a single case of suprasellar tumor with predominant meningothelial features near nests of granular cells (5). In these tumors, granular cells were indistinguishable from those seen in granular cell tumors of schwannian nature, the cytoplasmic granularity being due to accumulation of lysosomes [13].

Seven cases of a novel variant of meningioma showing oncocytic differentiation have recently been reported. Curiously enough, all these occurred in Italian pa- tients. These tumors were predominantly composed of large polygonal cells with finely granular eosinophilic cytoplasm and showed whorls, hyalinized vessels, and optically clear nuclear inclusions (Table 1). Neoplastic cells were also positive with antivimentin and anti-EMA antisera, and ultrastructurally showed desmosomes and interdigitating processes. Cytoplasmic granularity was due to mitochondria, resulting in a true oncocytic appearance. All the seven cases described displayed diffuse and intense immunoreactivity with antimitochondrial antiserum and, at the EM level, showed a large number of mitochondria in the cytoplasm $[2,13]$.

In our case, the histological and immunohistochemical features demonstrated the meningothelial origin of the tumor: the neoplastic cells were positive with anti-EMA, anti-vimentin, and focally positve with anti-cytokeratin, but negative with anti-S100 antisera. Ultrastructurally, the presence of numerous mitochondria in the cyto-

Table 1. Review of oncocytic meningioma

\begin{tabular}{|c|c|c|c|c|c|c|c|c|}
\hline Case & $\begin{array}{l}\text { Sex/age } \\
\text { (year) }\end{array}$ & Site & Follow-up & $\begin{array}{l}\text { Brain } \\
\text { invasion }\end{array}$ & Necrosis & Mitoses & $\begin{array}{l}\text { Nuclear } \\
\text { inclusions }\end{array}$ & $\begin{array}{l}\text { Prominent } \\
\text { nucleoli }\end{array}$ \\
\hline $1 *$ & $\mathrm{~F} / 54$ & Left sphenoid & $\begin{array}{l}\text { NED } \\
\text { (at } 82 \mathrm{mo} \text { ) }\end{array}$ & Absent & Present & $12 / 20$ & Present & Present \\
\hline $2 *$ & $\mathrm{~F} / 61$ & Falx & $\begin{array}{l}\text { Rec } \\
\text { (at } 18 \text { and } 27 \mathrm{mo} \text { ) }\end{array}$ & Absent & Present & $8 / 20$ & Present & Present \\
\hline $3 *$ & $\mathrm{~F} / 68$ & Left occipital & $\begin{array}{l}\text { Rec } \\
\text { (at } 30 \mathrm{mo} \text { ) }\end{array}$ & Absent & Present & $21 / 20$ & Present & Present \\
\hline $4 *$ & $\mathrm{M} / 73$ & Frontal & $\begin{array}{l}\text { NED } \\
\text { (at } 8 \text { mo) }\end{array}$ & Present & Absent & $6 / 20$ & Present & Present \\
\hline $5^{*}$ & $\mathrm{~F} / 55$ & Right parietotemporal & $\begin{array}{l}\text { Residual tumor } \\
\text { (at } 7 \mathrm{mo} \text { ) }\end{array}$ & Present & Present & $18 / 20$ & Present & Present \\
\hline $6 *$ & $\mathrm{~F} / 66$ & Right sphenoid & $\begin{array}{l}\mathrm{Rec} \\
\text { (at } 24 \mathrm{mo} \text { ) }\end{array}$ & Absent & Absent & $3 / 20$ & Present & Present \\
\hline $7^{\circ}$ & $\mathrm{F} / 78$ & Frontal & $\begin{array}{l}\text { NED } \\
\text { (at } 14 \text { mo) }\end{array}$ & Absent & Absent & rare & Present & Present \\
\hline $8^{\wedge}$ & $\mathrm{M} / 30$ & Right parietal & $\begin{array}{l}\text { NED } \\
\text { (at } 8 \mathrm{mo} \text { ) }\end{array}$ & Absent & Absent & $2 / 20$ & Present & Present \\
\hline
\end{tabular}

NED: no evidence of disease, Rec: recurrence, *Roncaroli F. et al. (1997) , ${ }^{\circ}$ Cimmino A. et al. (2000), ^present case 
plasm explains the granular appearance of almost all neoplastic cells, suggesting the diagnosis of oncocytic meningioma.

The low Ki-67 labeling and mitotic indices and focal positivity for cytokeratin do not allow us to exclude the occurrence of metastasis from an unknown site. The abundance of oncocytic cells resembles the oncocytic neoplasms at other sites, such as Hurthle tumor. However, anti-thyroglobulin immunostaining revealed the absence of this thyroid marker.

Accurate follow-up is necessary to exclude the presence of primitive tumors at other sites and to determine the prognostic value of the oncocytic variant. Some authors reported a favorable outcome in most oncocytic tumors, such as thyroid neoplasms [1, 16]. Nevertheless, at other sites such as the breast and pituitary, this morphological feature showed malignant behavior $[1,3$, 9, 11].

Similarly, the oncocytic variant of meningioma is probably more aggressive than the other ones; in the previously described cases, three patients relapsed, and infiltration of the brain cortex was present in two tumors; the proliferation index was high in all but one case. Moreover, in one case, there was infiltration of the parietal bone and of the overlying soft tissues with embolization of lymphatic vessels [13].

On the other hand, another recently described oncocytic meningioma showed a low proliferation index, absence of brain infiltration, and negative follow-up for neoplastic recurrence [2]. Moreover, our case appears to be less aggressive than the other oncocytic meningiomas reported in the literature. The absence of necrosis, dura infiltration, as well as the lack of vascular embolization and low mitotic index suggest benign behavior. At present, the patient remains free of recurrence.

In conclusion, further studies are necessary to ascertain whether this morphological variant does behave aggressively or not.

\section{References}

1. Chang A, Harawi SJ (1992) Oncocytes, oncocytosis, and oncocytic tumors. Pathol Annu 27(1): 263-304
2. Cimmino A, Giangaspero F, Pennella A, Serio G, De Tomasi A, Colamaria A, Ricco R (2000) Meningioma oncocitario. Descrizione di un caso. Pathologica 92: 82-85

3. Damiani S, Eusebi V, Losi L, D’Adda T, Rosai J (1998) Oncocytic carcinoma (malignant oncocytoma) of the breast. Am J Surg Pathol 22(2): 221-230

4. Davis CJ, Mostofi FK, Seterhenn IA, Ho CK (1991) Renal oncocytoma. Clinicopathologic study of 166 patients. J Urogen Pathol 112: 805-808

5. Friede RL, Yasargil MG (1977) Suprasellar neoplasm with a granular cell component. J Neuropathol Exp Neurol 26: 769-782

6. Giangaspero F, Cenacchi G (1999) Oncocytic and granular cell neoplasms of the central nervous system and pituitary gland. Sem Diagn Pathol 16: 91-97

7. Gotchell J, Traweek ST, Stenzel P(1987) Benign oncocytic endocrine tumor of the pancreas in a patient with polyarteritis nodosa. Hum Pathol 18: 967-969

8. Hamperl H (1962) Benign and malignant oncocytoma. Cancer 15: 1019-1027

9. Lewis HJE, Alexander CA, Fleming S (1986) Renal oncocytoma. Br J Urol 58: 12-15

10. Nappi O, Ferrara G, Wick MR (1999) Neoplasms composed of eosinophilic polygonal cells: an overview with consideration of different cytomorphologic patterns. Sem Diagn Pathol 16(2): 82-90

11. Okoye MI, Mueller WF (1983) Invasive pituitary oncocytoma. J Natl Med Ass 75: 1215-1219

12. Palmer TJ, Gleeson MJ, Eveson JW, Cowson RA (1990) Oncocytic adenomas and oncocytic hyperplasia of a salivary glands: a clinicopathological study of 26 patients. Histopathology 16: 487-493

13. Roncaroli F, Riccioni L, Cerati M, Capella C, Calbucci F, Trevisan C, Eusebi V (1997) Oncocytic meningioma. Am J Surg Pathol 21(4): 375-382

14. Russell DS, Rubinstein LJ (1989) Tumours of the meninges and related tissues. In Russell DS, Rubinstein LJ (Eds) Pathology of tumours of the nervous system. 5th ed. Edward Arnold; London 449-532

15. Takei Y, Mirra S, Miles M (1976) Eosinophilic granular cells in oligodendrogliomas. Cancer 38: 1968-1976

16. Tallini G, Carcangiu ML, Rosai J (1992) Oncocytic neoplasms of the thyroid gland. Acta Pathol Jpn 42: 305-315

Received: October 22, 2001

Accepted in revised version: December 7, 2001 